\title{
An investigation into fracture of multi-crystalline silicon
}

\author{
B.R. Mansfield, D.E.J. Armstrong, P.R. Wilshaw and J.D. Murphy ${ }^{a}$ \\ Department of Materials, University of Oxford, Parks Road, Oxford, OX1 3PH, UK \\ ajohn.murphy@materials.ox.ac.uk
}

Keywords: Multi-crystalline, silicon, mechanical properties, fracture, grain boundary.

\begin{abstract}
As the thickness of multi-crystalline silicon solar cells continues to reduce, understanding the mechanical properties of the material is of increasing importance. In this study, a variety of techniques are used to study multi-crystalline silicon. Fracture tests are performed using four- and three-point bending. The fracture stress of as-sawn material reduces with increasing beam width and is increased in beams with a polished front surface. This indicates that fracture initiates from surface flaws. Modifications to standard fracture testing, including testing under liquid, are made so that beams fracture into just two pieces. By determining the crystallography either side of the location of fracture, multi-crystalline silicon was found to fail by transgranular fracture in the samples studied. Further evidence for this is gained from indentation experiments at grain boundaries. In order to understand the relative strength of grain boundaries, new approaches need to be considered. Therefore, a novel micromechanical technique, which enables individual grain boundaries to be studied, has started to be applied to multi-crystalline silicon. A focused ion beam is used to mill micron-scale cantilevers across notched grain boundaries, which are then loaded to fracture using the tip of a nanoindenter. The technique is shown to reproduce the known fracture toughness of $\{110\}$ planes in single-crystal silicon, giving a value of $0.7 \pm 0.3 \mathrm{MPam}^{1 / 2}$. Preliminary results are presented for fracture of multi-crystalline silicon.
\end{abstract}

\section{Introduction}

The thickness of multi-crystalline silicon (mc-Si) wafers for photovoltaic applications has fallen considerably in recent years with sub- $200 \mu \mathrm{m}$ wafers now routinely used. The required reduction in cost per peak power output to reach grid parity requires substantial further reductions in thickness. Improving the mechanical properties of $\mathrm{mc}-\mathrm{Si}$ is therefore increasingly important.

Mechanical testing of single-crystal silicon has a long history and the material's properties are generally well understood (see [1] for a summary). However, mc-Si presents a new challenge, as it contains a host of crystal defects (including dislocations, grain boundaries, transition metal precipitates and silicon carbide/ silicon nitride precipitates) which are not generally significant in material used for integrated circuit applications. In order to improve the mechanical properties of mc-Si it is important first to understand how individual types of defects affect the fracture properties of the material. In this work, experiments are conducted which aim to study the fracture properties of different types of grain boundaries.

In recent years, with the increased availability of focused ion beam (FIB) machining and related techniques, micromechanical methods have developed which enable the properties of very small regions of crystals to be tested [2-6]. The advantage of these techniques is that they allow the mechanical effects of specific defects to be determined. In this paper, a micromechanical technique is applied to mc-Si to investigate the mechanical properties of individual grain boundaries. Existing methods [4] which use a FIB to prepare micron-scale cantilever specimens are applied to mc-Si. Compared to many materials, directionally-solidified mc-Si is a straightforward system on which to perform such experiments, as the grain boundaries run approximately normal to the wafer surface.

Preliminary results for the fracture toughness of grain boundaries are presented. In due course, it is hoped that the technique will allow the relationship between fracture toughness and grain boundary type to be understood fully. Furthermore, it should be possible to apply the technique to 
specific defects at grain boundaries, such as silicon carbide and silicon nitride precipitates, in order to ascertain their effects on mechanical properties of mc-Si wafers.

\section{Macroscopic fracture testing}

Method. The investigation was conducted on $200 \mu \mathrm{m}$ thick p-type mc-Si wafers with a resistivity of approximately $5 \Omega \mathrm{cm}$. The surface roughness of this as-sawn material was found to vary between $2.0 \mu \mathrm{m}$ and $8.8 \mu \mathrm{m}$ by optical profilometry. A wafer dicer was used to cut three sets of rectangular beams from this as-sawn material with length of approximately $20 \mathrm{~mm}$ and width $1.5,2.0$ or $2.5 \mathrm{~mm}$. Twenty specimens of each type were then fractured in four-point bending configuration (inner contact span: $10 \mathrm{~mm}$; outer contact span: $15 \mathrm{~mm}$ ). In a four-point bending configuration the load between the inner contacts is a maximum and constant, so a large proportion of the specimen is subjected to constant load. The loading was displacement-controlled at $0.05 \mathrm{~mm} / \mathrm{minute}$ and the testing was performed at room temperature.

As well as measuring stresses to fracture macroscopic samples, it was hoped fracture tests could determine the relative strengths of grain boundaries of different types. Key to this was ensuring that the fracture occurred in just one place. This was found not to be the case in the four-point bending experiments, so two other approaches were used. The first approach was to test the beam under conditions whereby there is a peak load in the centre of a beam and this was achieved by three-point bending on $2.0 \mathrm{~mm}$ wide beams (central to outer contact span: $7.5 \mathrm{~mm}$ ). The other approach was to reduce multiple fractures due to the sudden relaxation of the curvature of the beam at fracture which gives rise to bursts of flexural waves. This effect was investigated in raw spaghetti by Audoly and Neukirch [7] who concluded that the flexural waves locally increase the radius of curvature of the beam, and in some places beyond the critical radius of curvature so resulting in multiple fracture. This effect was overcome by performing the four-point bend test under liquid on $2.5 \mathrm{~mm}$ wide beams. Various liquids with different viscosities were tried and each had the effect of damping the flexural waves. Concentrated sugar solution (Golden Syrup) was found to work best. In many cases sticky tape was attached to the specimen, to facilitate easy location of the site of fracture.

Results and discussion. The results of the four-point bending fracture tests on the as-sawn beams are shown in Figure 1. It can be seen that the fracture stress reduces with increasing beam width. Since the beams are unpolished on both sides (and have unpolished wafer-diced edges), this suggests that fracture tends to initiate from flaws at the surface of the beams, as a greater area means more flaws and a higher probability of fracture at a given load.

The fracture data for four-point bending can be analysed in terms of Weibull statistics. If the fracture stresses in a set of brittle specimens are arranged in size order, the probability of survival of a given sample can be given by the following approximation:

$$
P_{\text {survival }}=\frac{n}{N+1}
$$

Where $n$ is the rank number of the sample and $N$ is the number of the samples in the set $(N=20$ in this case). This probability can be related to fracture stress, $\sigma$, on a Weibull plot, according to:

$$
\ln \left(-\ln \left(P_{\text {survival }}\right)\right)=m \ln \sigma-m \ln \sigma_{0}
$$

where $m$ is the Weibull modulus, and $\sigma_{0}$ is the scale parameter. Such a Weibull plot is presented in Figure 2, in which values of $m$ and $\sigma_{0}$ are given for all three sets of samples. 


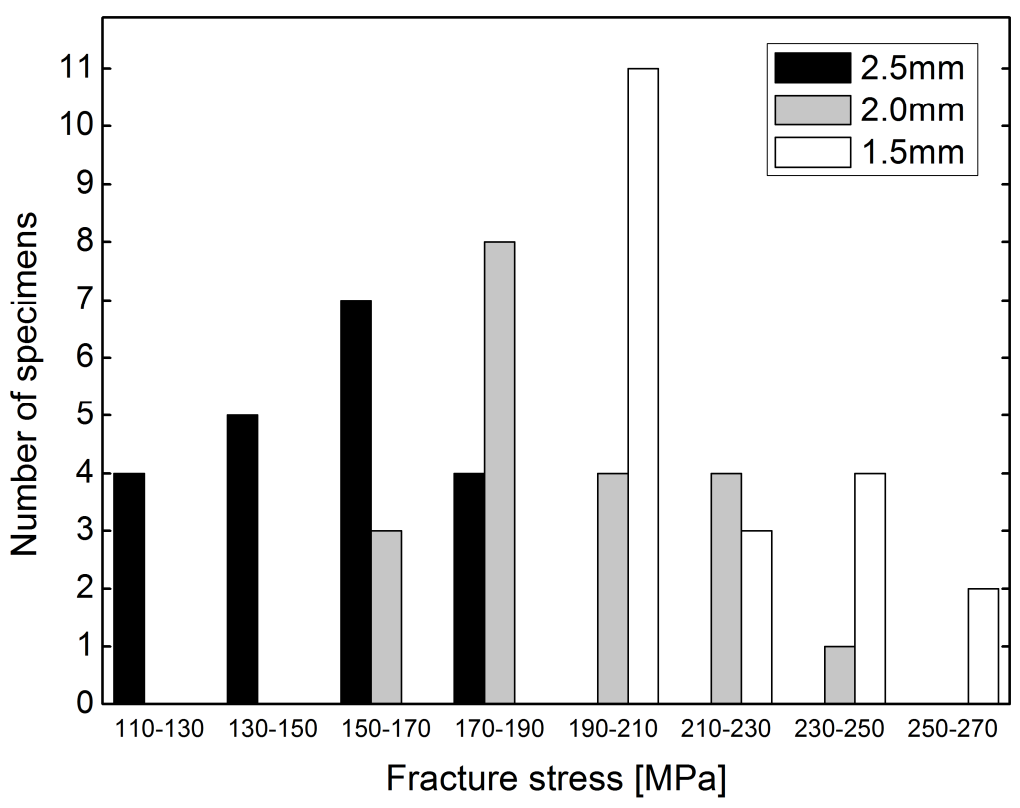

\begin{tabular}{|c|c|c|}
\cline { 2 - 3 } \multicolumn{1}{c|}{} & $\begin{array}{c}\text { Mean } \\
\text { fracture } \\
\text { stress } \\
{[\mathbf{M P a}]}\end{array}$ & $\begin{array}{c}\text { Standard } \\
\text { deviation } \\
{[\mathbf{M P a}]}\end{array}$ \\
\hline $2.5 \mathrm{~mm}$ & 149 & 20 \\
\hline $2.0 \mathrm{~mm}$ & 193 & 20 \\
\hline $1.5 \mathrm{~mm}$ & 217 & 21 \\
\hline
\end{tabular}

Figure 1. Distribution of fracture stresses measured by four-point bending in as-sawn mc-Si beams with different widths.

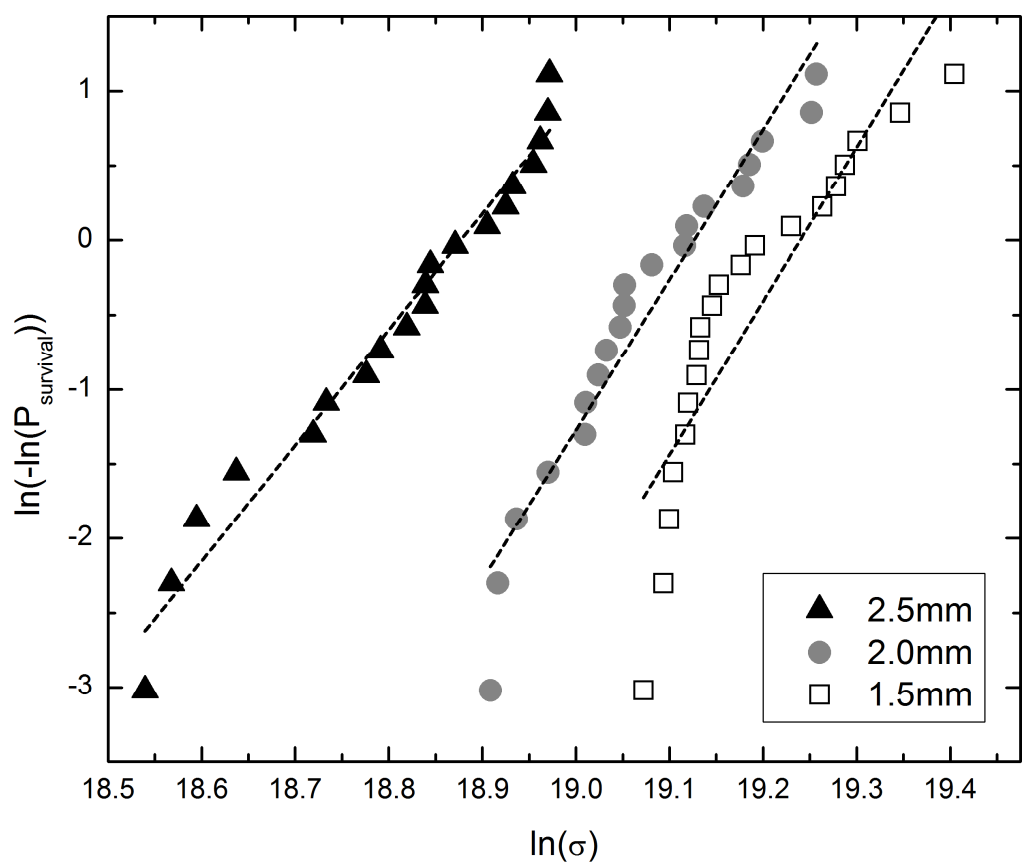

\begin{tabular}{|c|c|c|}
\cline { 2 - 3 } \multicolumn{1}{c|}{} & $\mathbf{m}$ & $\boldsymbol{\sigma}_{\mathbf{0}}[\mathbf{M P a}]$ \\
\hline $2.5 \mathrm{~mm}$ & 7.8 & 158 \\
\hline $2.0 \mathrm{~mm}$ & 10.1 & 203 \\
\hline $1.5 \mathrm{~mm}$ & 10.3 & 227 \\
\hline
\end{tabular}

Figure 2. Weibull plot and Weibull parameters for unpolished mc-Si beams with different widths.

All of the 60 as-sawn samples tested by four-point bending presented in Figure 1 fractured into more than two pieces. With three-point bending, all seven beams tested in this way all fractured in just one place. The peak stress fracture stress was $225 \mathrm{MPa}$, with a standard deviation of 50MPa. With four-point bending under liquid, 11 of the 20 as-sawn beams fractured under concentrated sugar solution fracture into just two pieces. The fracture stress of these $2.5 \mathrm{~mm}$ wide beams had a mean value of $156 \mathrm{MPa}$, with a standard deviation of $19 \mathrm{MPa}$. This fracture stress is consistent with that presented in Figure 1.

In order to characterize the site of fracture, electron backscatter diffraction (EBSD) was performed either side of the fracture location. However, in order to perform EBSD a well-polished surface is needed. Consequently the tensile face of a set of $2.5 \mathrm{~mm}$ wide mc-Si beams was polished to a colloidal silica finish and these were fractured under concentrated sugar solution. The mean fracture stress of these 20 beams was $218 \mathrm{MPa}$ with a standard deviation of $65 \mathrm{MPa}$. The increase in mean fracture stress from the data presented in Figure 1 is consistent with the argument that critical 
surface flaws are sites for fracture initiation. The larger scatter in the data is thought to be due to the additional edge flaws that are introduced during the polishing process (the edges were left as-diced).

Figure 3 shows a mc-Si beam fractured under concentrated sugar solution to give a single fracture and mounted with the two parts of the beam rejoined. EBSD was used to determine the orientation of the crystal on either side of the fracture site. The EBSD results show that the crystallography on both sides of the fracture site is the same, i.e. the fracture crossed a grain. Many more examples of such transgranular failure were found. No inter-granular fracture was observed.
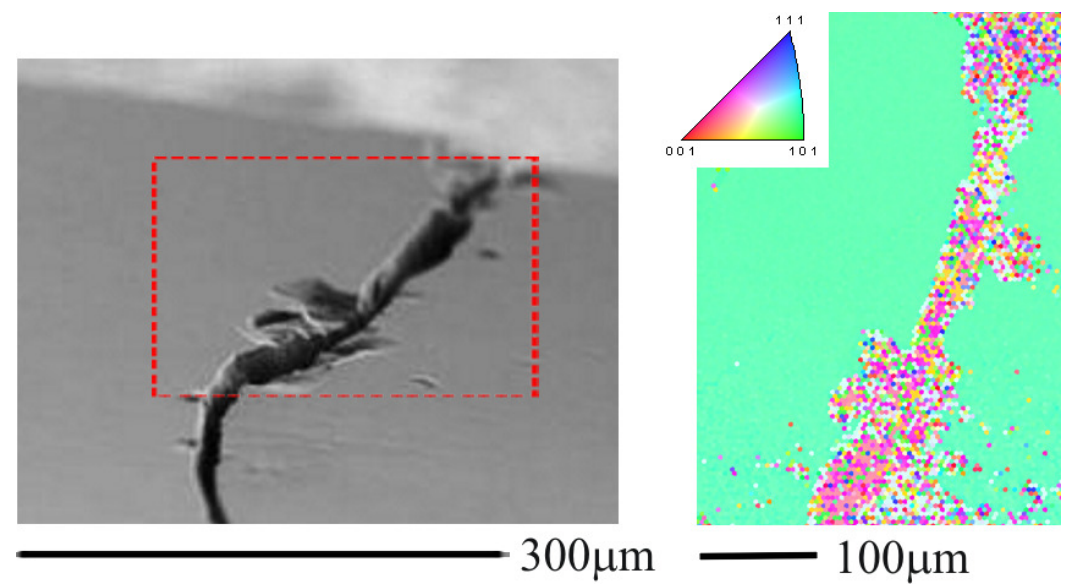

Figure 3. Secondary electron image of a fractured mc-Si specimen (left). The EBSD grain orientation map (right) shows failure occurred across a grain rather than at a grain boundary. The specimen had a polished front surface and was fractured under a concentrated sugar solution.
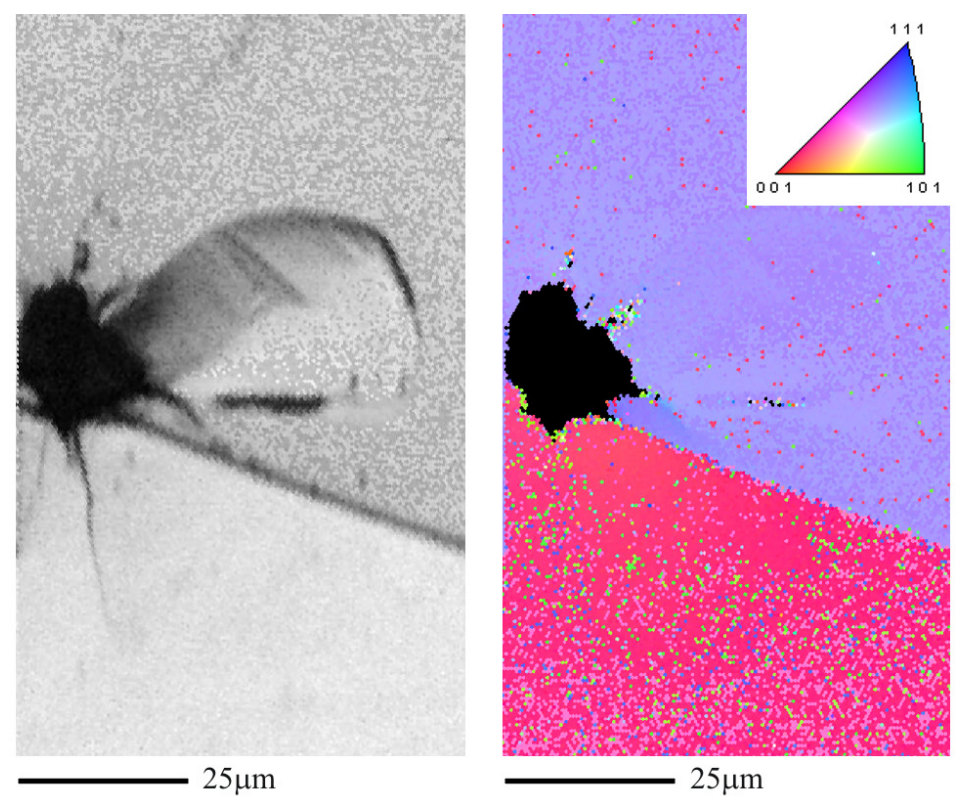

Figure 4. Secondary electron micrograph (left) showing an indent and resultant crack not propagating along grain boundary. The EBSD grain orientation map (right) indicates a $\Sigma=19$ grain boundary with misorientation $38.3^{\circ}$

\section{Indentation in the vicinity of grain boundaries}

From the fracture tests it was clear that transgranular failure was occurring, suggesting that grain boundaries are not substantially weaker than the bulk. Another set of experiments was devised in order to try to measure the strengths of grain boundaries. Samples of mc-Si were mirror polished, down to a $40 \mathrm{~nm}$ colloidal silica finish. A light etch was used to reveal the grain boundaries. A Vickers diamond indenter was used with a $500 \mathrm{~g}$ load and a $15 \mathrm{~s}$ dwell time to make indents in the 
vicinity of grain boundaries. By measuring the crack length along the grain boundary it would be possible to estimate the grain boundary fracture toughness in the material [8].

Figure 4 shows one example of the many indents made next to grain boundaries in mc-Si. The location and misorientation of the grain boundary was verified by EBSD. It can be seen that the radial cracks appear not to have an affinity to the grain boundary and do not act to break it apart. This is further evidence that the grain boundaries studied in mc-Si are not substantially weaker than the bulk.

\section{Micromechanical testing}

Method. With fracture testing and indentation not able to isolate grain boundary fracture, a novel micromechanical approach is in progress. The same material used in the macroscopic testing was polished mechanically and chemomechanically, down to a 40nm colloidal silica finish. EBSD was used to map the sample, to determine the crystallography of the grains present. The sample was then subjected to a one minute etch in $75 \mathrm{HNO}_{3}(70 \%): 8 \mathrm{HF}(40 \%): 17 \mathrm{CH}_{3} \mathrm{COOH}$ (glacial), which just revealed the grain structure without substantially attacking the grain boundaries. A single-crystal float-zone silicon (FZ-Si) sample was used as a control. This material was n-type (phosphorus doped) with a resistivity of $30 \pm 10 \Omega \mathrm{cm}$ and had a surface normal along [001].

Microcantilevers are fabricated using a FEI FIB 200 in a four-stage process, as follows:

1. A beam current of 3 to $5 \mathrm{nA}$ is used to mill a $6 \mu \mathrm{m}$ deep ' $U$-shaped' trench

2. A beam current of approximately $300 \mathrm{pA}$ is passed over the side walls of the central arm. This cleans the beams, ensuring that re-deposited material is removed from the edges

3. The stage is then tilted to $45^{\circ}$ and a rectangle is milled using a $300 \mathrm{pA}$ beam current to remove material from under the central arm. This process is repeated on the other side of the beam to produce a cantilever with pentagonal cross-section, as shown in Figure 5(a)

4. A $10 \mathrm{pA}$ beam current is used to mill a $0.5 \mu \mathrm{m}$ deep notch across the width of the beam near the fixed end. In the case of $\mathrm{mc}-\mathrm{Si}$, this notch was introduced along the grain boundary

The beams were fractured by applying a load with a Berkovich diamond tip in an MTS NANO Indenter XP. Before testing, the specimen was first scanned using the indenter tip as an atomic force microscope (AFM), as shown in Figure 5(b). This allowed the end of the beam to be located accurately. The load was applied with a displacement rate of $5 \mathrm{~nm} / \mathrm{s}$.
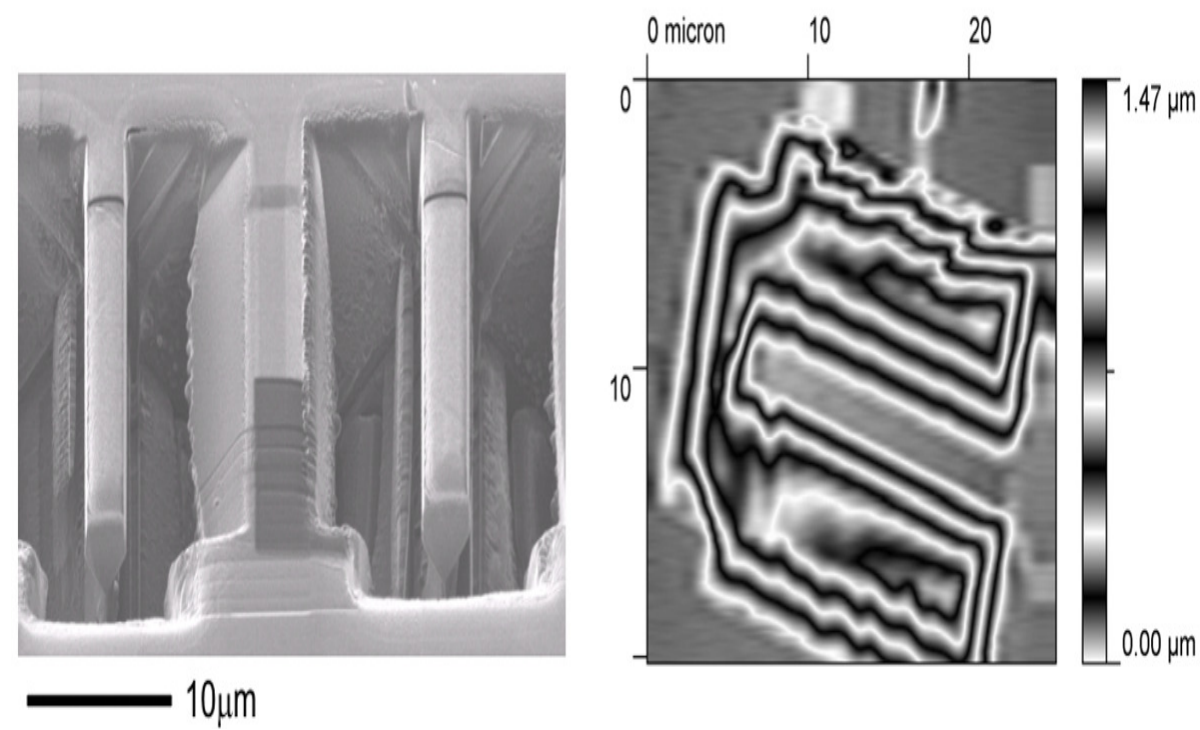

Figure 5. (a) Two microcantilevers at a grain boundary at mc-Si with a $57.3^{\circ}$ misorientation (left). Notches have been made on the cantilevers at the grain boundary. (b) A scan of a cantilever in mcSi made using the nanoindenter in AFM-mode (right). 
Results and discussion. In order to check the validity of the micromechanical technique, cantilevers were first fabricated and fractured in single-crystal FZ-Si. Six cantilevers were milled into a (001) surface with their long axis along $<110>$. A notch was inserted normal to the long axis. The nanoindenter was used to measure the fracture load and this was converted, using the analysis described in [4] using dimensions measured from secondary electron images, to give a mean fracture toughness of $0.7 \mathrm{MPam}^{1 / 2}$, with a standard deviation of $0.3 \mathrm{MPam}^{1 / 2}$. Within experimental error, this is consistent with the known value of fracture toughness for this fracture plane of $0.89 \mathrm{MPam}^{1 / 2}[9]$.

Microcantilevers were then fabricated at grain boundaries in mc-Si and were fractured. The preliminary results obtained are presented in Table 1. This remains work in progress, but initial results suggest that grain boundaries are no weaker than the bulk.

\begin{tabular}{|c|c|c|c|c|c|c|}
\hline $\begin{array}{l}\text { Grain mis- } \\
\text { orientation }\end{array}$ & $\begin{array}{l}\text { GB plane - } \\
\text { cantilever } \\
\text { side }\end{array}$ & $\begin{array}{l}\text { GB plane - } \\
\text { bulk side }\end{array}$ & $\begin{array}{c}\text { Rotation } \\
\text { axis of } \\
\text { planes }\end{array}$ & $\begin{array}{c}\text { Number of } \\
\text { cantilevers } \\
\text { tested }\end{array}$ & $\begin{array}{l}\text { Fracture } \\
\text { toughness } \\
\left(\mathrm{MPam}^{1 / 2}\right)\end{array}$ & $\begin{array}{l}\text { Standard } \\
\text { deviation } \\
\left(\text { MPam }^{1 / 2}\right)\end{array}$ \\
\hline $12.5^{\circ}$ & $\left(\begin{array}{lll}1 & 7 & 13\end{array}\right)$ & $\left(\begin{array}{lll}20 & 17 & \overline{1}\end{array}\right)$ & {$\left[\begin{array}{lll}9 & \overline{10} & \overline{27}\end{array}\right]$} & 4 & 1.1 & 0.2 \\
\hline $35.6^{\circ}$ & $\left(\begin{array}{lll}21 & \overline{2} & 14\end{array}\right)$ & $\left(\begin{array}{lll}\overline{3} & \overline{22} & \overline{10}\end{array}\right)$ & {$\left[\begin{array}{lll}17 & 0 & 8\end{array}\right]$} & 4 & 1.3 & 0.2 \\
\hline $47.7^{\circ}$ & $\left(\begin{array}{lll}\overline{7} & 4 & \overline{15}\end{array}\right)$ & $\left(\begin{array}{lll}\overline{22} & \overline{9} & 15\end{array}\right)$ & {$[\overline{23} \quad 18 \quad 4]$} & 4 & 1.2 & 0.2 \\
\hline
\end{tabular}

Table 1. Fracture toughness of grain boundaries in mc-Si as a function of grain misorientation.

\section{Summary}

The mechanical properties of mc-Si have been investigated. Methods have been developed which give single fractures of beam specimens. Fracture testing results show that, for the conditions studied, grain boundaries are not substantially weaker than the bulk. These results, together with the results of indentation experiments, support the argument that mc-Si fails by transgranular fracture. It is clear that new approaches are needed to study the fracture properties of individual grain boundaries. Preliminary results of a novel micromechanical technique have been presented. Further investigations using this technique could relate grain boundary type to fracture strength and could be used to investigate the effect of precipitates at grain boundaries on mechanical properties.

\section{Acknowledgements}

The authors thank Dr S. Senkader and Prof. S.G. Roberts for useful discussions and REC Wafer for provision of mc-Si. Dr J.D. Murphy is the grateful recipient of a Royal Academy of Engineering/ EPSRC Research Fellowship and a Junior Research Fellowship at St Anne's College, Oxford.

\section{References}

[1] Properties of Crystalline Silicon edited by R. Hull, Chapter 3, Structural and Mechanical Properties (edited by A. George). INSPEC, London (1999)

[2] S.P. Baker, W.D. Nix, J. Mater. Res., 93131 (1994)

[3] M.D. Uchic, D.M. Dimiduk, Mater. Sci. Eng. A, 400268 (2005)

[4] D. Di Maio, S.G. Roberts, J. Mater. Res., 20299 (2005)

[5] D. Kiener, C. Motz, T. Schöbert, M. Jenko, G. Dehm, Adv. Eng. Mater., 81119 (2006)

[6] F.M. Halliday, D.E.J. Armstrong, J.D. Murphy, S.G. Roberts, Advanced Materials Research, 59 304 (2009)

[7] B. Audoly, S. Neukirch, Phys. Rev. Lett., 95095505 (2005)

[8] G.R. Anstis, P. Chantikul, B.R. Lawn, D.B. Marshall, J. Am. Ceram. Soc., 64533 (1981)

[9] G. Michot, A. George, Inst. Phys. Conf. Ser., 104385 (1988) 